\title{
First Reply to: Delayed surgery in displaced paediatric supracondylar fractures: a safe approach? Results from a large UK tertiary paediatric trauma centre
}

\author{
James S. Huntley
}

Received: 9 September 2013/Accepted: 29 September 2013/Published online: 22 October 2013

(C) Springer-Verlag France 2013

\section{Dear Editor}

I was interested to read the article 'Delayed surgery in displaced paediatric supracondylar fractures: a safe approach? Results from a large UK tertiary paediatric trauma centre' by Mayne et al. [1]. This study purports to show that 'delayed surgery appears to offer a safe management approach to the treatment of displaced supracondylar fractures', in part because of the lack of significant differences in complication rates between those operated on before and after $12 \mathrm{~h}$.

A close reading of this manuscript shows that the alleged 'iatrogenic nerve injury rate' was $10.4 \%(12 / 115)$. This is much higher than the $3.9 \%$ for iatrogenic neurapraxia after closed reduction and percutaneous pinning from a recent meta-analysis [2]. Unfortunately, Mayne et al. [1] do not provide a figure for the traumatic preoperative nerve injury rate. These data are important, not only because adverse neurology might influence the timing of surgery (and therefore affect case allocation to the 'early' or 'delayed' group), but also in that, it might account (in part) for the large post-operative nerve injury rate.

In the event, data relevant to this question have been published from this same case series (137 patients with supracondylar humeral fractures observed in a 2-year period from July 2008 to July 2010) previously [3]. The earlier manuscript [3] was cited in [1], but only in relation to the sentence: 'to help ensure that adequate assessment is undertaken, we have previously reported on the

J. S. Huntley $(\bowtie)$

Royal Hospital for Sick Children, Dalnair Street,

Yorkhill, Glasgow G3 8SJ, UK

e-mail: james.huntley@glasgow.ac.uk development of an assessment proforma to ensure children with indications for emergency intervention are identified' This earlier manuscript [3] involved the same 137 patients (I believe), but concerned the documentation of neurovascular status-crucially, it found that only $12(8.8 \%)$ had a complete pre-operative neurological assessment documented.

Since the pre-operative nerve injury rate is unassessable from this data set, does it not follow that the true rate of iatrogenic nerve injury in this study is also unknowable?

Apparent equivalence in apparently high complication rates from non-randomised groups can at best be taken as 'absence of evidence'. It would be unwise to extrapolate this conclusion to 'evidence of absence'. In conclusion, the data are simply not sound enough to warrant the authors' assertion that 'delayed surgery appears to offer a safe management approach to the treatment of displaced supracondylars'.

Conflict of interest None.

\section{References}

1. Mayne AIW, Perry DC, Bruce CE (2013) Delayed surgery in displaced paediatric supracondylar humeral fractures: a safe approach? Results from a large UK tertiary paediatric trauma centre. Eur J Orthop Surg Traumatol (Epub ahead of print)

2. Babal JC, Mehlman CT, Klein G (2010) Nerve injuries associated with pediatric supracondylar humeral fractures: a meta-analysis. J Pediatr Orthop 30:253-263

3. Mayne AIW, Perry DC, Stable G, Dhotare S, Bruce CE (2013) Documentation of neurovascular status in supracondylar fractures and the development of an assessment proforma. Emerg Med J 30:480-482 